NASA/TM-2012-217292

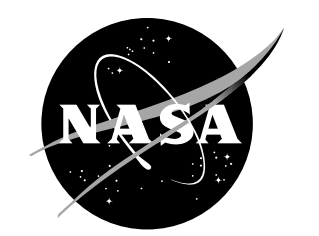

\title{
Overview of Heat Addition and Efficiency Predictions for an Advanced Stirling Convertor
}

Scott D. Wilson, Terry V. Reid, Nicholas A. Schifer, and Maxwell H. Briggs

Glenn Research Center, Cleveland, Ohio 


\section{NASA STI Program . . . in Profile}

Since its founding, NASA has been dedicated to the advancement of aeronautics and space science. The NASA Scientific and Technical Information (STI) program plays a key part in helping NASA maintain this important role.

The NASA STI Program operates under the auspices of the Agency Chief Information Officer. It collects, organizes, provides for archiving, and disseminates NASA's STI. The NASA STI program provides access to the NASA Aeronautics and Space Database and its public interface, the NASA Technical Reports Server, thus providing one of the largest collections of aeronautical and space science STI in the world. Results are published in both non-NASA channels and by NASA in the NASA STI Report Series, which includes the following report types:

- TECHNICAL PUBLICATION. Reports of completed research or a major significant phase of research that present the results of NASA programs and include extensive data or theoretical analysis. Includes compilations of significant scientific and technical data and information deemed to be of continuing reference value. NASA counterpart of peer-reviewed formal professional papers but has less stringent limitations on manuscript length and extent of graphic presentations.

- TECHNICAL MEMORANDUM. Scientific and technical findings that are preliminary or of specialized interest, e.g., quick release reports, working papers, and bibliographies that contain minimal annotation. Does not contain extensive analysis.

- CONTRACTOR REPORT. Scientific and technical findings by NASA-sponsored contractors and grantees.
- CONFERENCE PUBLICATION. Collected papers from scientific and technical conferences, symposia, seminars, or other meetings sponsored or cosponsored by NASA.

- SPECIAL PUBLICATION. Scientific, technical, or historical information from NASA programs, projects, and missions, often concerned with subjects having substantial public interest.

- TECHNICAL TRANSLATION. Englishlanguage translations of foreign scientific and technical material pertinent to NASA's mission.

Specialized services also include creating custom thesauri, building customized databases, organizing and publishing research results.

For more information about the NASA STI program, see the following:

- Access the NASA STI program home page at http://www.sti.nasa.gov

- E-mail your question via the Internet to help@ sti.nasa.gov

- Fax your question to the NASA STI Help Desk at $443-757-5803$

- Telephone the NASA STI Help Desk at 443-757-5802

- Write to: NASA Center for AeroSpace Information (CASI) 7115 Standard Drive Hanover, MD 21076-1320 
NASA/TM-2012-217292



Overview of Heat Addition and Efficiency Predictions for an Advanced Stirling Convertor

Scott D. Wilson, Terry V. Reid, Nicholas A. Schifer, and Maxwell H. Briggs

Glenn Research Center, Cleveland, Ohio

Prepared for the

9th International Energy Conversion Engineering Conference (IECEC)

sponsored by the American Institute of Aeronautics and Astronautics

San Diego, California, July 31-August 3, 2011

National Aeronautics and

Space Administration

Glenn Research Center

Cleveland, Ohio 44135 


\section{Acknowledgments}

This work is funded through the National Aeronautics and Space Administration (NASA) Science Mission Directorate and the Radioisotope Power Systems Program Office. The authors wish to acknowledge the many people who supported this testing and analysis effort including Art Atherton, Kamran Daryabeigi, Wayne Gerber, Dave Gubics, Nissim Lugasy, and the vision and guidance of Jeff Schreiber.

This report is a formal draft or working paper, intended to solicit comments and ideas from a technical peer group.

This report contains preliminary findings, subject to revision as analysis proceeds.

Trade names and trademarks are used in this report for identification only. Their usage does not constitute an official endorsement, either expressed or implied, by the National Aeronautics and Space Administration.

Level of Review: This material has been technically reviewed by technical management.

Available from

NASA Center for Aerospace Information 7115 Standard Drive

Hanover, MD 21076-1320
National Technical Information Service 5301 Shawnee Road Alexandria, VA 22312 


\title{
Overview of Heat Addition and Efficiency Predictions for an Advanced Stirling Convertor
}

\author{
Scott D. Wilson, Terry V. Reid, Nicholas A. Schifer, and Maxwell H. Briggs \\ National Aeronautics and Space Administration \\ Glenn Research Center \\ Cleveland, Ohio 44135
}

\begin{abstract}
The U.S. Department of Energy (DOE) and Lockheed Martin Space Systems Company (LMSSC) have been developing the Advanced Stirling Radioisotope Generator (ASRG) for use as a power system for space science missions. This generator would use two high-efficiency Advanced Stirling Convertors (ASCs), developed by Sunpower Inc. and NASA Glenn Research Center (GRC). The ASCs convert thermal energy from a radioisotope heat source into electricity. As part of ground testing of these ASCs, different operating conditions are used to simulate expected mission conditions. These conditions require achieving a particular operating frequency, hot end and cold end temperatures, and specified electrical power output for a given net heat input. Microporous bulk insulation is used in the ground support test hardware to minimize the loss of thermal energy from the electric heat source to the environment. The insulation package is characterized before operation to predict how much heat will be absorbed by the convertor and how much will be lost to the environment during operation. In an effort to validate these predictions, numerous tasks have been performed, which provided a more accurate value for net heat input into the ASCs. This test and modeling effort included: (a) making thermophysical property measurements of test setup materials to provide inputs to the numerical models, (b) acquiring additional test data that was collected during convertor tests to provide numerical models with temperature profiles of the test setup via thermocouple and infrared measurements, (c) using multidimensional numerical models (computational fluid dynamics code) to predict net heat input of an operating convertor, and (d) using validation test hardware to provide direct comparison of numerical results and validate the multidimensional numerical models used to predict convertor net heat input. This effort produced high fidelity ASC net heat input predictions, which were successfully validated using specially designed test hardware enabling measurement of heat transferred through a simulated Stirling cycle. The overall effort and results are discussed.
\end{abstract}

\section{Nomenclature}

\begin{tabular}{|c|c|}
\hline $\mathrm{ASC}(-\mathrm{E} 2)$ & Advanced Stirling Convertor (for the second generation Engineering Unit) \\
\hline $\operatorname{ASRG}(-\mathrm{EU})$ & Advanced Stirling Radioisotope Generator (Engineering Unit) \\
\hline CFD & computational fluid dynamic \\
\hline CSAF & cold-side adapter flange \\
\hline DOE & Department of Energy \\
\hline EU & Engineering Unit \\
\hline FEA & finite element analysis \\
\hline GPHS & General Purpose Heat Source \\
\hline GRC & Glenn Research Center \\
\hline LaRC & Langley Research Center \\
\hline LMSSC & Lockheed Martin Space Systems Company \\
\hline RPS & Radioisotope Power System \\
\hline TPRL & Thermophysical Properties Research Laboratory Inc. \\
\hline
\end{tabular}




\subsection{Introduction}

Stirling power conversion technology is being developed for space flight by the U.S. Department of Energy (DOE), Lockheed Martin Space Systems Company (LMSSC), Sunpower, Inc., and the NASA Glenn Research Center (GRC). NASA GRC has been testing high-efficiency free-piston Stirling convertors for potential use in Radioisotope Power Systems (RPSs) since 1999. The current effort is in support of the Advanced Stirling Radioisotope Generator (ASRG), which has demonstrated significantly higher system efficiency in comparison to radioisotope thermoelectric generators, reducing the amount of fuel $(\mathrm{Pu} 238)$ required by a factor of four (Ref. 1).

Convertor and generator testing is carried out in tests designed to characterize convertor performance when subjected to environments intended to simulate launch and space conditions. These conditions require maintaining a particular operating frequency, piston amplitude, and convertor temperatures (hot end, cold end, and alternator) while achieving a specified electrical power output for a given net heat input. Figure 1 shows a simplified example of how net heat input can be calculated if all values for heat flux are known. More complex formulations involving internal surfaces of heat exchangers can be used to calculate net heat input but are not discussed here. Stirling convertor net heat input is defined as the sum of heat energy supplied to the Stirling cycle and heat energy lost from the hot end to the cold end of the machine (known as cold end losses). Inherent to all heat engines, cold end losses are minimized by design but still play a significant role in the power budget. In this example, net heat input is the heat energy not lost back to the environment before it is consumed by the cycle or lost to the cold end. Testing involves developing support hardware that enables 24/7 unattended operation and data collection, including control and data acquisition systems, heating and cooling components, and general mounting and insulation packages. Microporous bulk insulation is used in the ground support test hardware to minimize the loss of thermal energy from the electric heat source to the environment.

Before operation, the insulation package is subjected to various temperature conditions during insulation loss characterization to quantify how much heat will be absorbed by the convertor and how much will be lost to the environment during operation. This characterization enables the calculation of net heat input to the convertor and efficiency at a given operating point. Calculation of net heat input has historically been done by curve fitting the insulation loss characterization data, but such a method has never been validated. In an effort to validate net heat input predictions, numerous tasks have been



Simplified Example of Net Heat Input to Convertor

(1) - Heat addition to Heater Head from Heat Source

(2) - Heat Loss from Collector to Support Hardware

(3) - Heat Loss from Cylinder to Support Hardware Example calculation:

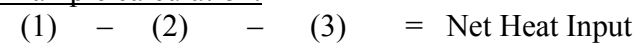

$220 \mathrm{~W}-10 \mathrm{~W}-1 \mathrm{~W}=209 \mathrm{~W}$

Figure 1.-Simplified example of net heat input. 
performed that provided a more accurate value for net heat input to the Advanced Stirling Convertors (ASCs). These tasks, discussed in more detail in later sections, include a) making thermophysical property measurements of test setup materials to provide inputs to the numerical models, b) acquiring additional test data that is collected during convertor tests to provide numerical models with temperature profiles of the test setup, c) using multidimensional numerical models to predict net heat input of an operating convertor, and d) using validation test hardware to provide direct comparison between measured data and numerical results to validate the multidimensional numerical models used to predict convertor net heat input (and efficiency).

\subsection{Convertor Testing}

The ASC was developed by Sunpower, Inc., under contract to NASA GRC with technical support from GRC. It was designed to produce a nominal 80 We from $250 \mathrm{~W}$ gross heat input when integrated into a generator. The ASC-E convertors utilize Inconel 718 heater heads while the ASC-E2, -E3, and Flight convertors utilize MarM-247 heater heads, which operate at a maximum hot end temperature of 650 and $850{ }^{\circ} \mathrm{C}$, respectively. The cold end temperature operating range is 40 to $90{ }^{\circ} \mathrm{C}$ for the ASC-E. The operating range has been expanded significantly to 15 to $124^{\circ} \mathrm{C}$ for the ASC-E2. A heat collector is attached to the hot end of the heater head, which interfaces to an electric heat source during laboratory operation. A conductive flange called the cold side adapter flange has been attached to the heat rejection zone of the convertor that allows attachment of cooling loops.

\subsection{Ground Support Hardware}

Figure 2 shows ASC-E2s mounted in a vertical orientation and dual-opposed configuration. The ground support hardware was developed to provide proper heating and cooling of the convertor while supporting a single convertor in vertical orientation (heater head up) or a dual-opposed pair of convertors in either horizontal or vertical orientation (Ref. 2). Electric heaters and fluid cooling loops are used to control the temperatures of the hot and cold ends of the Stirling convertor. As the convertor design transitioned from the ASC-E, which has an Inconel heater head to the ASC-E2 and future units that all have MarM heater heads, the convertor hot end temperature increased from 650 to $850{ }^{\circ} \mathrm{C}$. The electric heat source temperature required to maintain the $850{ }^{\circ} \mathrm{C}$ hot end temperature in ground tests increased (approaching $1,000{ }^{\circ} \mathrm{C}$ ) as well. This proved to be problematic with standard cartridge heaters because they were not rated for operation above $760{ }^{\circ} \mathrm{C}$. As such, the heat sources typically only lasted a few hundred hours, which delayed testing of convertors at the desired conditions. To enable long-duration

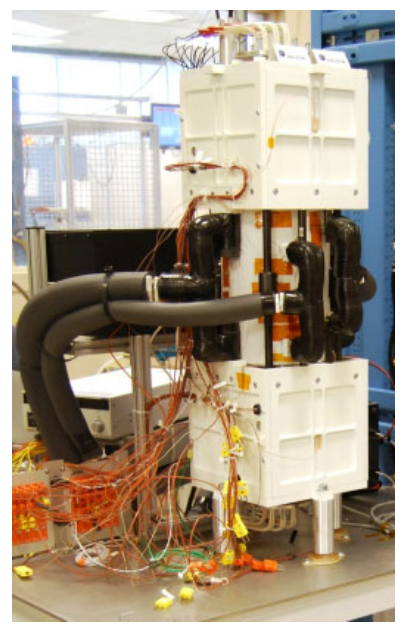

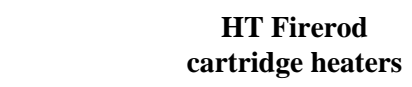

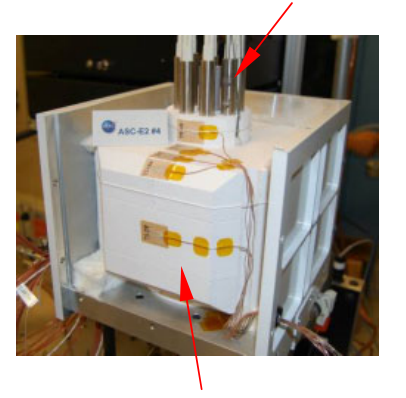

Microsil microporous bulk insulation
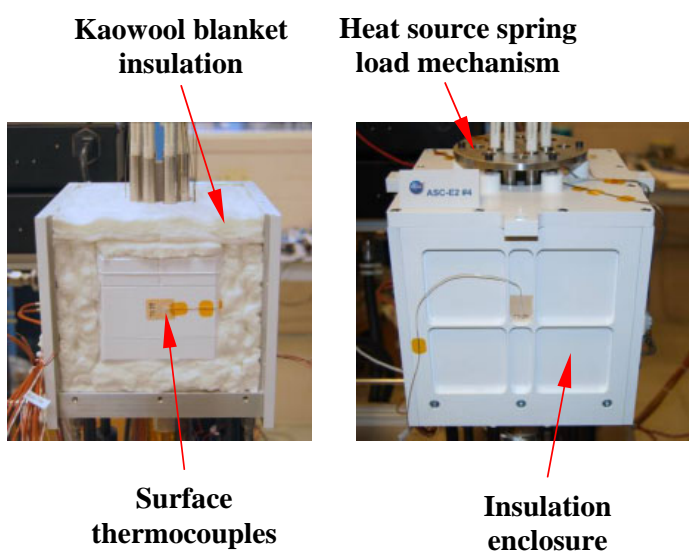

Figure 2.--Insulation package for ASC-E2 testing. ASC-E2s \#3 and \#4 shown mounted in a vertical orientation and dual-opposed configuration (left) and ASC-E2 \#4 shown at different stages of insulation assembly. 


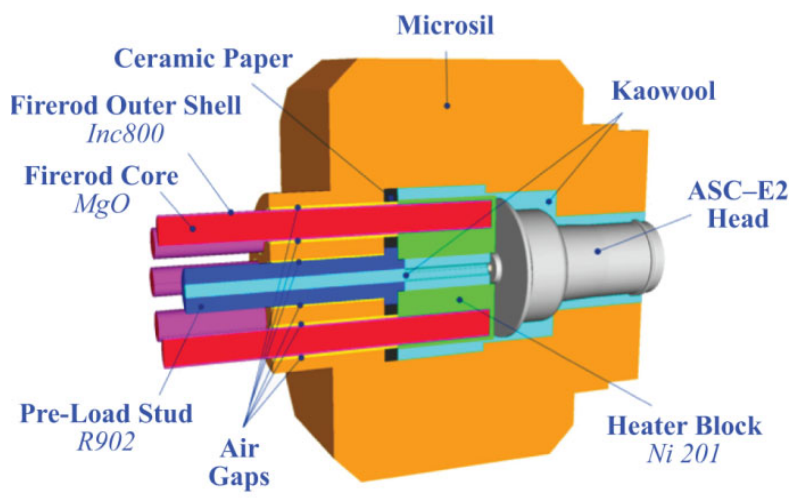

Figure 3.-ASC-E2 HT Firerod heat source. HT Firerod cartridge heaters (red) and nickel block (green)

shown.

$850{ }^{\circ} \mathrm{C}$ convertor tests, a high-temperature heat source development activity was initiated. In addition to down selecting to a new heat source design, the insulation package was redesigned to minimize heat loss from the heat source to the environment during operation. Also shown in Figure 2 are the HT Firerod cartridge heaters, insulation package, heat source load mechanism, and insulation enclosure.

The insulation enclosure is used for mounting the convertor and many test components including the heat source, cooling plumbing, and bulk insulation. The enclosures, machined from aluminum, have been designed to the representative size and general shape of the ASRG-EU housing. The enclosures house the Microsil microporous insulation used to minimize heat loss from the heat source to the environment during operation. The insulation package is made of several different types of insulation including microporous insulation, ceramic paper, and Kaowool (Morgan Thermal Ceramics) blanket insulation. Figure 3 shows the different areas where each type of insulation was used and how the heat source locates against the hot end of the Stirling convertor heater head (labeled "ASC-E2 Head"). The heat source is spring loaded against the convertor heater head using a Cotronics Rescor ceramic load stud, which has a temperature limit of $1150^{\circ} \mathrm{C}$. Firerod heat source temperatures can exceed $1,000{ }^{\circ} \mathrm{C}$ when operating with an $850^{\circ} \mathrm{C}$ acceptor temperature due to the roughly $90 \mathrm{~W}$ of additional heat energy lost to the environment compared to a completely enclosed, yet shorter life, version of the heat source. The Microsil microporous insulation has a temperature limit of $1,000{ }^{\circ} \mathrm{C}$, so the Kaowool blanket and ceramic paper insulations, which have a temperature limit of above $1100^{\circ} \mathrm{C}$, were used to separate the Microsil from heat source. Thermocouples were located inside the test setup to monitor internal temperatures and gather data for thermal modeling tasks.

\subsection{Insulation Loss Characterization}

Performance tests are used to test convertors for acceptance and characterization. Before performance testing can begin, insulation loss characterization is performed to determine environmental losses for different convertor temperature profiles. The heat source and convertor are subjected to various temperature profiles and convertor parasitic losses, or cold end losses (parasitic heat losses transferred from the hot end to the cold end of the convertor through conduction, convection, and radiation) are calculated via one-dimensional models. The cold end losses are subtracted from the measured gross heat input to the electric heaters to calculate the environmental loss. Calculation of net heat input has historically been achieved by curve fitting the environmental loss to a reference temperature. Typically, the heat source is chosen as a reference temperature due to its strong influence on thermal gradients in the test setup. However, these curve fits are limited because they rely on the assumption that the cold end losses and temperature profiles are accurately represented for an operating convertor during a nonoperating test. Single parameter and multiparameter correlations have been shown to contain a bias error of around $13 \mathrm{~W}$, despite using a weighted average reference temperature over a heat source 
reference temperature (Ref. 3). Also, it is assumed that the closed form equations used to calculate convertor parasitic losses accounted for all of the static and dynamic losses present in an operating convertor. Actually, thermodynamic second law available energy losses in an operating convertor are of the following general types: (1) mass flow across a pressure difference (viscous dissipation), (2) heat transfer across a temperature difference, and (3) mixing of fluids at different initial temperatures (Refs. 4 and 5). Viscous dissipation losses in the regenerator and heat exchangers, displacer shuttle losses, regenerator thermal dispersion, and losses from mixing of fluids at different initial temperatures have not typically been included in the calculation of cold end losses while heat transfer across a temperature difference has typically been accounted for. A greater limitation of using curve fits is the dependence on the assumption that nonoperating test data accurately represents the temperature profile of an operating convertor. The convertor and insulation package temperature profiles, used to calculate heat conduction through the convertor to the cold side adapter flange (CSAF), change when the convertor is operating so there is an unquantifiable error associated with curve fitting environmental losses to a reference temperature, despite which temperature is chosen as a reference.

\subsection{Predictions of Convertor Net Heat Input}

Net heat input cannot be directly measured on an operating convertor. The validation effort focused on being able to actually predict net heat input on a devise with a temperature profile very similar to that of an operating convertor. Figure 4 outlines the measured and predicted values of net heat input available from test and numerical methods. The Thermal Standard and Stirling convertors share all available methods except measured net heat input on an operating convertor. One key assumption made by the validation effort is that validating numerical models of the Thermal Standard provides confidence in the results from numerical models used to represent an operating convertor.

Paramount to the convertor modeling effort was the assumption that the predicted temperature profile governed the resulting heat transfer through modeled components. With that in mind, one major goal was to match predicted temperatures to measured temperatures by adjusting the various resistance paths inherent to the materials and component interfaces present in the model. Resistance paths were tuned by adjusting the interface resistance between two mating solid components. The interface resistance was modified only between the heat source/heat collector plate interface for convertor models and between the
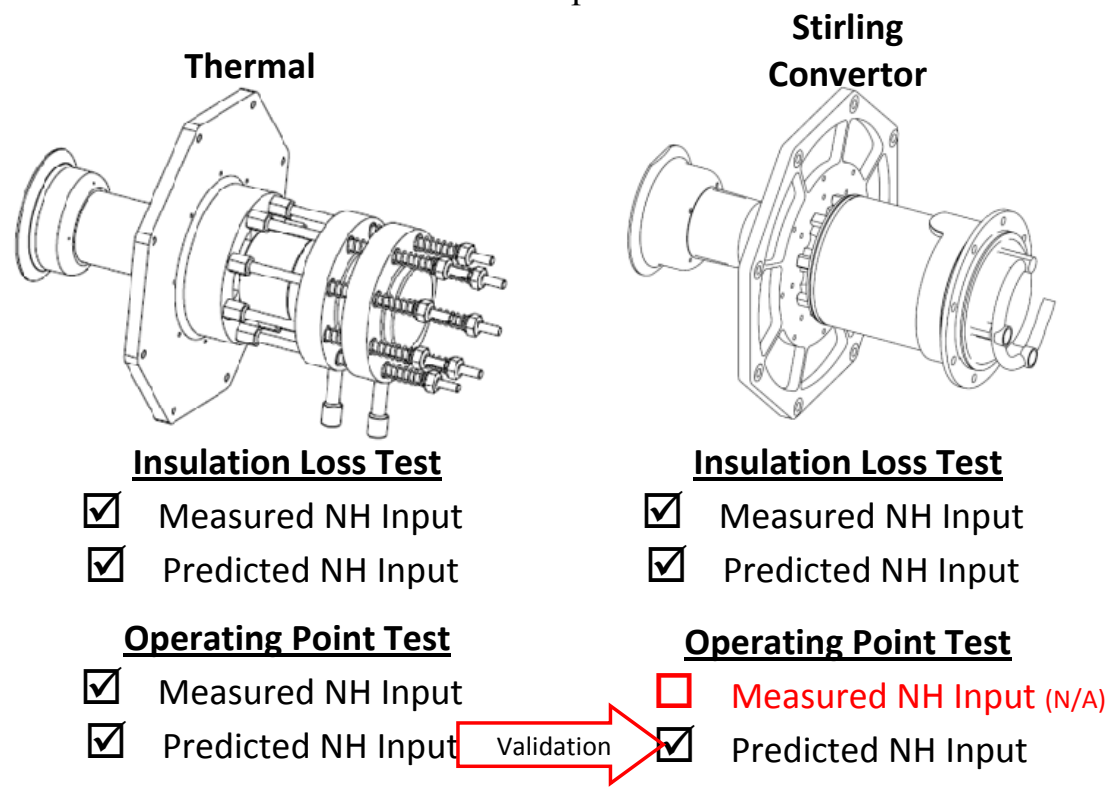

Figure 4.-Net heat input values available from testing and analysis. Measurement of convertor net heat input is not possible. 
heat source/heat collector plate interface and internal acceptor/conduction rod interface for the Thermal Standard model. Resistance paths were also tuned by offsetting thermal conductivity for a given insulation material. Figure 3 shows several types of insulation used in the test setup, including Microsil microporous insulation, Kaowool blanket, magnesium oxide (heaters), and ceramic paper. Each of the insulation materials had a corresponding thermophysical property data available from literature. In the case of the bulk microporous insulation, test measurements were made to acquire a more accurate value of the temperature-dependent thermal conductivity. This material test value had an inherent \pm 7 percent uncertainty according to Thermophysical Properties Research Laboratory Inc. (TPRL). Furthermore, the geometric size of an insulation component decreases slightly, or shrinks, and effectively changes the optical transparency of the insulation to radiation heat transfer. As new insulation pieces are exposed to high-temperature parts during tests, the thermal conductivity increases until the package stops shrinking, which is expected to happen at around 4 percent volume decrease for the type of insulation used in ASC ground tests.

Leading up to the validation, numerous tasks were performed, which provided more accurate inputs and boundary conditions for numerical models. Thermophysical property measurements were made of the microporous bulk insulation used to insulate the hot components in the Thermal Standard test setup and to provide more accurate inputs for the materials. Additional temperatures were acquired throughout the ASC test setup (external surfaces and internal probes) to provide numerical models with temperature profiles. These test temperatures were used as boundary conditions and as targets for which the numerical results could be compared. Nonlinear temperature profiles were also acquired via infrared images of the heater assembly components surfaces exposed to air and, therefore, affected by natural and forced convection. These inputs were used in multidimensional numerical models designed to predict net heat input of an operating convertor.

In an effort to improve input into the numerical model, insulation material testing was performed. Figure 5 shows results provided by TPRL and NASA Langley Research Center (LaRC). The vendor data is also shown (Zircar M-sil 2). The tests were performed on various microporous insulations used in ASC tests. The thermophysical properties measured using the laser flash method (ASTM E1461), included density, specific heat, thermal diffusivity, and thermal conductivity (Ref. 6). Thermal conductivity was measured for the microporous insulation materials used in GRC tests (Microsil Type 2, M-sil 2) and in Sunpower tests (Microsil Type 1, M-sil 1). There are three curves that represent the M-sil 1 material used in convertor tests performed at Sunpower, Inc. Similarly, there are four curves that represent the M-sil 2 insulation material used in convertor tests performed at NASA GRC. The M-sil 2 labels correspond to unaged and aged conditions: aged data from TPRL, unaged data from TPRL, and unaged data from LaRC.

Thermal Conductivity for Various

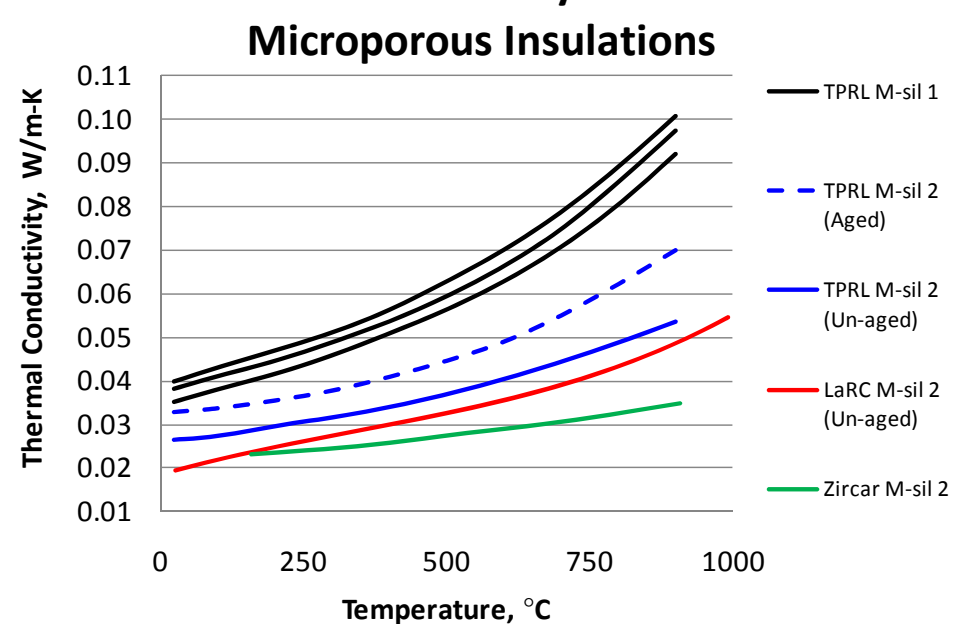

Figure 5.-Thermal conductivity measurements. 
Prior to having received the aged insulation material test data, the Microsil thermal conductivity was increased in the numerical model by an arbitrary amount required to get resulting temperatures to match measured temperatures. It was later revealed, after having received the aged data, that the thermal conductivity used and the thermal conductivity from the aged insulation were within 5 percent, suggesting that the aged data well represents the condition of the insulation used in the test. The lesson learned was that the insulation should be baked out prior to use in testing in order to accelerate degradation. This aging process was performed at $800{ }^{\circ} \mathrm{C}$ for $12 \mathrm{hr}$, which was expected to shrink the insulation from 2 to 4 percent. This technique bypasses the slow aging that would normally happen due to exposure of the heat source after a test has started.

\subsection{Validation Effort}

In addition to high-fidelity computational fluid dynamic (CFD) models, a validation effort was performed to provide evidence that the CFD models were grounded in reality and, in turn, quantify the accuracy of ASC net heat input predictions. Validation test hardware provided direct comparison between measured data and numerical results to validate the multidimensional numerical models used to predict convertor net heat input. This effort consisted of two separate test assemblies, the Mock Heater Head and Thermal Standard. Test conditions were used that attempted to simulate the temperature profile of an operating convertor using static heat conduction through solid components. This enabled direct calculation of heat transferred through the test setup and provided a comparison to numerical results. The test data was also used to constrain the numerical models. For example, the measured heat addition to the cartridge heater assembly was used as the gross heat input to the model. The measured temperatures from exterior surfaces of the convertor, insulation, and support hardware were also used as model boundary conditions. This included infrared images used to represent the temperature profiles for the heater assembly surfaces exposed to air. Each convertor and test point was treated as an individual case. The data was collected from convertor tests and used in 1) the insulation loss test case, which was used to tune heat transfer resistance values for various materials and interfaces and 2) the operating point test case, which was used to acquire the proper net heat input. For both modeled cases, the success criteria was to achieve a close match of predicted and measured temperatures. Thermocouples were placed at key locations throughout the test setup, as shown in Figure 6, to enable tuning of various interface resistances and bulk thermal conductivities. These temperature measurements were matched at least within the measurement error, but of often much better, of the temperature readings ranging from 300 to $1,000{ }^{\circ} \mathrm{C}$.

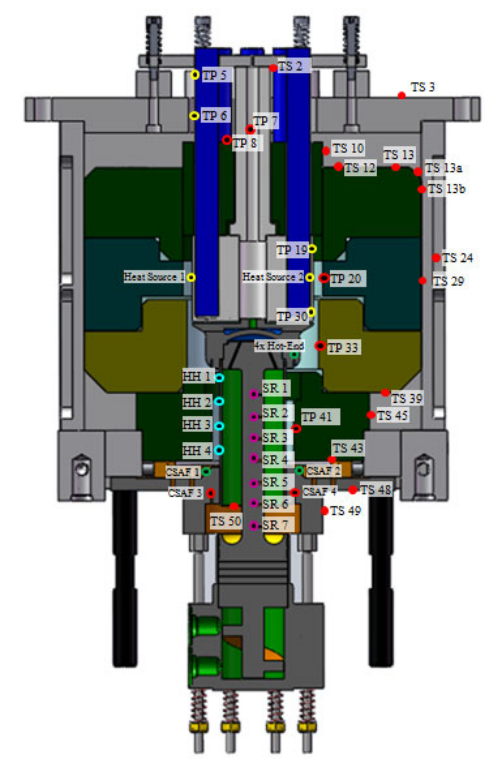

Figure 6.-Thermal standard thermocouple diagram. 


\subsection{Mock Heater Head}

Prior to the design of the Thermal Standard, a test setup was designed using an existing version of the heater head used in past testing and some new components including a rod fabricated from a special type of high-strength copper and a CSAF fabricated from oxygen-free high-thermal conductivity copper. This hardware enabled conduction through a cylinder wall normally present in convertor testing and a rod, which was used to simulate the additional heat absorbed by the Stirling cycle (called the conduction rod). Testing was carried out over a number of hot end and CSAF temperatures (Ref. 7). The Mock Heater Head hardware served as a pathfinder for the Thermal Standard test, in that it enabled the selection of materials and coatings used for the conduction rod, identified desired design features for the heat collector, internal acceptor, and CSAF. It also identified the desired thermocouple locations for calculating heat conducted to the cold end, heat rejection system mounting method for ease of disassembly and shipment, and preferred test methods used for characterization, such as how to control the heat input.

For the conduction rod, GRCop-84, a high-strength copper design at GRC was used as it has superior strength at expected temperatures compared to traditional copper (Refs. 8 and 9). The material has exceptional corrosion resistance up to $650{ }^{\circ} \mathrm{C}$. To protect from planned exposure to higher temperatures, the rod was nickel plated. Small-diameter probe thermocouples were then tack welded onto the nickel plated surface. The Mock Heater Head test exposed the nickel plated GRCop- 84 to an estimated $500{ }^{\circ} \mathrm{C}$ for over $1,500 \mathrm{hr}$ while the Thermal Standard test exposed it's rod to an estimated $700{ }^{\circ} \mathrm{C}$ for just under $1,000 \mathrm{hr}$. The conduction rods were inspected after each test and were found to be in relatively good condition, meaning there was an insignificant oxide layer present. Additionally, diffusion bonding between the rod and heater head was prevented in both tests by installing a thin layer $(<0.010 \mathrm{in}$.) of Cotronics ceramic paper between the heater block and head.

The Mock Heater Head test data was also used as boundary conditions in a finite element analysis (FEA) simulation to predict the contribution of environmental heat loss from the exposed portion of the heater assembly. Figure 7 shows the truncated model, which consisted of the hot surfaces of the heat source assembly, the electrical connections with ceramic beads, and the load plate that compressed the heater load stud during assembly. This model was used to provide an estimate of how much more heat is lost while simulating an operating convertor compared to insulation loss characterization. Originally believed to be large, the additional heat lost to the environment from the hot surfaces of the heater assembly was less than $3 \mathrm{~W}$ for an increase in gross heat input of $194 \mathrm{~W}$, which is within 10 percent of the expected increase for a convertor. This same exercise was performed domains of the Thermal Standard and ASC-E2 \#7 and the results were similar.


Figure 7.-Firerod heat source assembly thermal analysis. Infrared image (left) and truncated domain used to represent surfaces affected by convection heat transfer (right). 


\subsection{Net Heat Input Predictions for Thermal Standard}

The Thermal Standard, shown in Figure 8, is the test hardware designed to provide validation data for the modeling approach employed to predict net heat input for convertors. This test hardware allowed predicted values of net heat input to be compared directly to measured values. A computational model of the Thermal Standard hardware was used to perform calculations of net heat input (Ref. 10). These calculations used boundary conditions obtained during the testing of the Thermal Standard hardware in the GRC Stirling Research Laboratory. Test conditions included Insulation Loss Characterization, which were used to simulate a non-operating convertor, and simulated operation of a convertor. The Thermal Standard is a device that was constructed to simulate the thermal gradients that would exist in the ASC-E2. The total heat addition or net heat input into the Stirling convertor is difficult to measure experimentally due to the inability to accurately measure the environmental losses from the hot insulation package during operation.

During lab experiments, Fourier's Law was used to calculate the heat conducted through the copper rod based on test measurements. The corresponding rod heat transfer is $208.7 \mathrm{~W}$ where $\mathrm{k}=316 \mathrm{~W} / \mathrm{m} / \mathrm{K}, \mathrm{D}=0.014 \mathrm{~m}, \mathrm{~A}=$



Figure 8.-Thermal standard hardware (top) and predicted temperatures (bottom). $1.539 \mathrm{E}-04 \mathrm{~m}^{2}, \Delta \mathrm{T}=309^{\circ} \mathrm{C}$, and $\Delta \mathrm{x}=0.072 \mathrm{~m}$. The same calculation was performed for the stainless steel heater head cylinder wall, which resulted in $35.7 \mathrm{~W}$. Operating conditions from the Thermal Standard resulted in $208.7 \mathrm{~W}$ of heat conducted through the rod, used to simulate the Stirling cycle, and $35.7 \mathrm{~W}$ of heat conducted through the heater head cylinder, resulting in a net heat input value of $244.4 \mathrm{~W}$. Similarly, the modeling approach resulted in $205.5 \mathrm{~W}$ of heat conducted through the rod and $34.8 \mathrm{~W}$ of heat conducted through the heater head cylinder wall. This resulted in a net heat input value of $240.3 \mathrm{~W}$. Figure 8 also shows the resulting temperatures for the case discussed. The predicted value of net heat input was 1.7 percent less than that measured during testing. Enhancements were made to the model over time, which included adding additional heat transfer modes and improved boundary conditions. This resulted in a model with higher fidelity and robust boundary conditions.

\subsection{Net Heat Input Predictions for Stirling Convertors}

Convertor net heat input predictions were produced for several ASC-E2s during December 2010. After the validation effort had concluded in March 2011, several lessons learned during the validation exercise were applied to the previous convertor predictions. The lessons learned included the need for (a) enhanced heat transfer due to the inclusion of radiation heat transfer near the interior surfaces of the heater head, (b) separating the Kaowool blanket insulation surrounding the heat source and heater head into three sections to allow better control over the resulting temperatures at measured temperature locations, and (c) changing the magnesium oxide thermal conductivity present in the HT Firerod cartridge heaters from a constant input to a temperature dependent input. Net heat input and convertor efficiency was reported during December 2010 for the Beginning of Mission Low Reject operating point performed on ASC-E2 \#7. The resulting net heat input reported was $213.9 \mathrm{~W}$. The corresponding efficiency, based on a terminal power output of $84.9 \mathrm{~W}$, was 39.7 percent. That case was updated using lessons learned during the validation exercise. The updated net heat input and corresponding efficiency were $216.3 \mathrm{~W}$ and 39.3 percent. Figure 9 shows the resulting temperature profile for the updated case. 


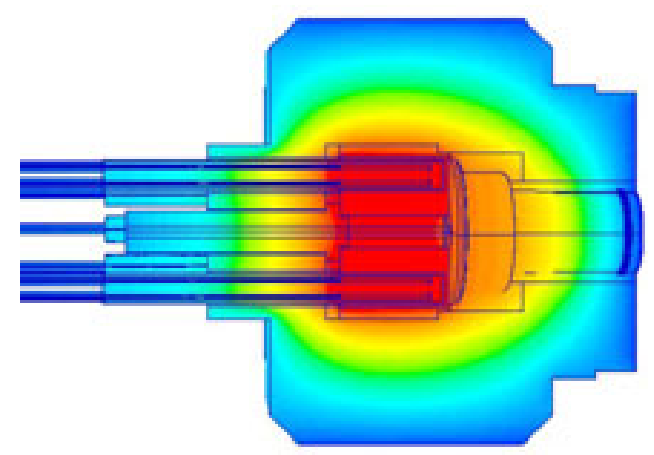

Figure 9.-Convertor computational domain and predicted temperatures.

\subsection{Conclusion}

Convertor and generator testing is carried out in tests designed to characterize convertor performance when subjected to environments intended to simulate launch and space conditions. These conditions require achieving a particular operating frequency, hot end and cold end temperatures, and power output for a given net heat input. The value of net heat input must be known to validate convertor efficiency. In an effort to improve the accuracy of the efficiency calculation, numerous tasks have been performed, which provided a more accurate value for net heat input into the Advanced Stirling Convertors (ASCs). This test and modeling effort included: (a) making thermophysical property measurements of test setup materials to provide inputs to the numerical models, (b) acquiring additional test data that was collected during convertor tests to provide numerical models with temperature profiles of the test setup via thermocouple and infrared measurements, (c) using multidimensional numerical models (CFD codes) to predict net heat input of an operating convertor, and (d) using validation test hardware to provide direct comparison of numerical results and validate the multidimensional numerical models used to predict net heat input. This effort produced high fidelity ASC net heat input predictions, which were successfully validated using specially designed test hardware enabling measurement of heat transferred through a simulated Stirling cycle.

\section{References}

1. Schreiber, J.G., Thieme, L.G., Wong, W.A., "Supporting Technology at GRC to Mitigate Risk as Stirling Power Conversion Transitions to Flight," Proceedings of the Sixth International Energy Conversion Engineering Conference (IECEC 2008), American Institute of Aeronautics and Astronautics, 2008.

2. Oriti, S., Wilson, S.D., "Advanced Stirling Convertor (ASC-E2) Performance Testing at NASA Glenn Research Center," Proceedings of the First Nuclear and Emerging Technologies for Space (NETS 2011), Feb. 2011.

3. Briggs, M.H., Schifer, N.A., "Evaluation of Advanced Stirling Convertor Net Heat Input Correlation Methods using a Thermal Standard," Proceedings of the Ninth International Energy Conversion Engineering Conference (IECEC 2011), American Institute of Aeronautics and Astronautics, 2011.

4. Tew, R.C., Overview of Heat Transfer and Fluid Flow Problem Areas Encountered in Stirling Engine Modeling, NASA TM-100131, Feb. 1988.

5. Wilson, S.D., Dyson, R.W., Tew, R.C., Ibrahim, M.B., "Multi-D CFD Modeling of a Free-Piston Stirling Convertor at NASA GRC," Proceedings of the Second International Energy Conversion Engineering Conference (IECEC 2004), American Institute of Aeronautics and Astronautics, 2004. 
6. Daryabeigi, K., Cunnington, G.R., Miller, S.D., Knutson, J.R., "Combined Heat Transfer in HighPorosity High-Temperature Fibrous Insulations: Theory and Experimental," AIAA 2010-4660. Validation.

7. Schifer, N.A., Briggs, M.H., "Environmental Loss Characterization of an ASC-E2 Insulation Package using a Mock Heater," Proceedings of the Ninth International Energy Conversion Engineering Conference (IECEC 2011), American Institute of Aeronautics and Astronautics, 2011.

8. Ellis, David L., and Keller, Dennis J., "Thermophysical Properties of GRCop-84," NASA/CR2000-210055, 2000.

9. Ellis, David L., "GRCop-84: A High-Temperature Copper Alloy for High-Heat-Flux Applications," NASA/TM-2005-213566, 2005.

10. Reid, T.V., Wilson, S.D, Schifer, N.A., Briggs, M.H., "A Computational Methodology for Simulating Thermal Loss Testing of the Advanced Stirling Convertor," Proceedings of the Ninth International Energy Conversion Engineering Conference (IECEC 2011), American Institute of Aeronautics and Astronautics, 2011. 


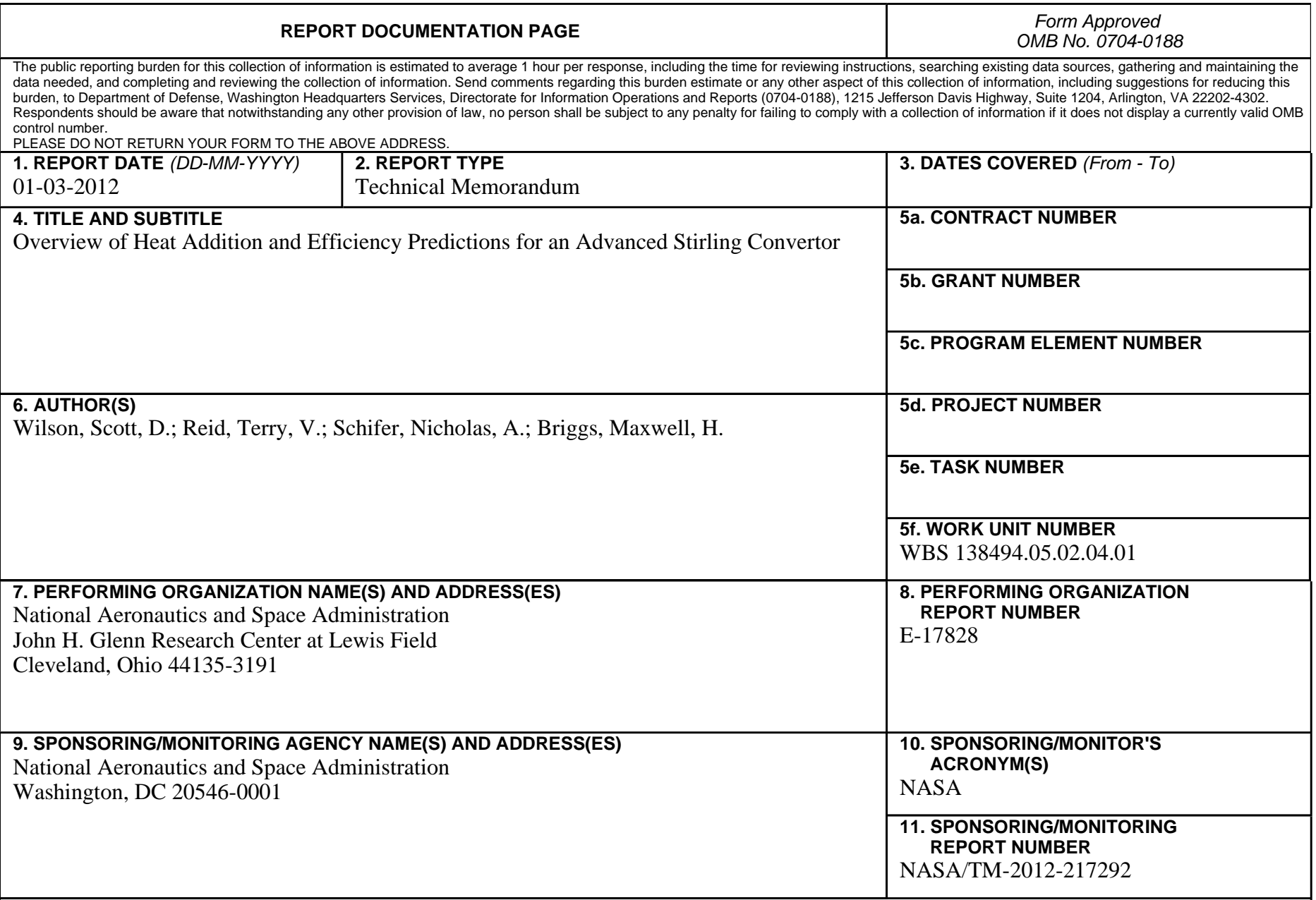

\section{DISTRIBUTIONIAVAILABILITY STATEMENT}

Unclassified-Unlimited

Subject Category: 20

Available electronically at http://www.sti.nasa.gov

This publication is available from the NASA Center for AeroSpace Information, 443-757-5802

\section{SUPPLEMENTARY NOTES}

\section{ABSTRACT}

The U.S. Department of Energy (DOE) and Lockheed Martin Space Systems Company (LMSSC) have been developing the Advanced Stirling Radioisotope Generator (ASRG) for use as a power system for space science missions. This generator would use two high-efficiency Advanced Stirling Convertors (ASCs), developed by Sunpower Inc. and NASA Glenn Research Center (GRC). The ASCs convert thermal energy from a radioisotope heat source into electricity. As part of ground testing of these ASCs, different operating conditions are used to simulate expected mission conditions. These conditions require achieving a particular operating frequency, hot end and cold end temperatures, and specified electrical power output for a given net heat input. Microporous bulk insulation is used in the ground support test hardware to minimize the loss of thermal energy from the electric heat source to the environment. The insulation package is characterized before operation to predict how much heat will be absorbed by the convertor and how much will be lost to the environment during operation. In an effort to validate these predictions, numerous tasks have been performed, which provided a more accurate value for net heat input into the ASCs. This test and modeling effort included: (a) making thermophysical property measurements of test setup materials to provide inputs to the numerical models, (b) acquiring additional test data that was collected during convertor tests to provide numerical models with temperature profiles of the test setup via thermocouple and infrared measurements, (c) using multidimensional numerical models (computational fluid dynamics code) to predict net heat input of an operating convertor, and (d) using validation test hardware to provide direct comparison of numerical results and validate the multidimensional numerical models used to predict convertor net heat input. This effort produced high fidelity ASC net heat input predictions, which were successfully validated using specially designed test hardware enabling measurement of heat transferred through a simulated Stirling cycle. The overall effort and results are discussed.

\section{SUBJECT TERMS}

Stirling convertor; Performance verification; Computational fluid dynamics (CFD); Heat addition predictions; Radioisotope power system

\begin{tabular}{|c|c|c|c|}
\hline \multicolumn{3}{|c|}{ 16. SECURITY CLASSIFICATION OF: } & \multirow{2}{*}{$\begin{array}{l}\text { 17. LIMITATION OF } \\
\text { ABSTRACT } \\
\text { UU }\end{array}$} \\
\hline $\begin{array}{l}\text { a. REPORT } \\
U\end{array}$ & $\begin{array}{l}\text { b. ABSTRACT } \\
U\end{array}$ & $\begin{array}{l}\text { c. THIS } \\
\text { PAGE } \\
\text { U }\end{array}$ & \\
\hline
\end{tabular}

18. NUMBER
OF
PAGES
18

19a. NAME OF RESPONSIBLE PERSON STI Help Desk (email:help@sti.nasa.gov) 19b. TELEPHONE NUMBER (include area code) 443-757-5802 

